\title{
CHARACTERISTICS OF SEISMIC EXCITATIONS IN CORINTH GULF (GREECE)
}

\author{
Mesimeri M. ${ }^{1}$, Karakostas V. ${ }^{1}$, Papadimitriou E. ${ }^{1}$ and Tsaklidis G. ${ }^{2}$ \\ ${ }^{1}$ Department of Geophysics, Aristotle University of Thessaloniki, GR54124, Thessaloniki, Greece, \\ mmesimer@geo.auth.gr,vkarak@geo.auth.gr,ritsa@geo.auth.gr \\ ${ }^{2}$ Department of Statistics and Operational Research, Aristotle University of Thessaloniki, \\ GR54124,Thessaloniki, Greece, tsaklidi@math.auth.gr
}

\begin{abstract}
Seismic excitations occur as mainshock-aftershock sequences (MS-AS) encompassing a strong event called mainshock with the largest magnitude in the set, or as earthquake swarms (ES) when a distinctive main event is absent. In regions as the gulf of Corinth, where active deformation is manifested with frequent seismicity bursts, it is important to distinguish MS-AS from ES for providing information on the physical process of earthquake generation and contribute to the seismic hazard assessment. For this purpose, a highly accurate local earthquake catalogue was compiled and an effort was made for clusters identification after establishing certain criteria based on spatio-temporal seismicity properties. The skewness and kurtosis of moment release history were calculated considering the normalized time of every event in a cluster since the starting time of the cluster and its seismic moment. For MS-AS we found large positive values for skewness and kurtosis contrary to ES that exhibit negative to low positive values for skewness and even lower values for kurtosis. In order to verify the classification of clusters, the b-value, the spatial size and the number of events of each cluster were examined. Finally, a scaling relation between the length of the rupture zone and magnitude derived for the MS-AS sequences.

Keywords: main shock, swarms, relocation, skewness, b-value, statistical seismology.
\end{abstract}

\section{Пєрí}

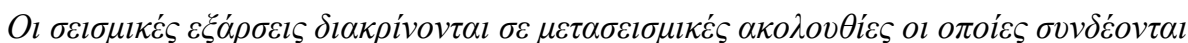

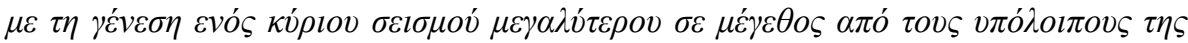

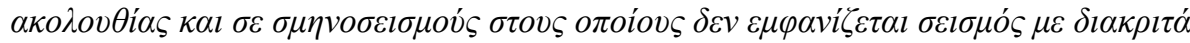

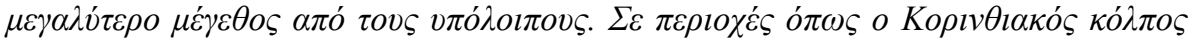

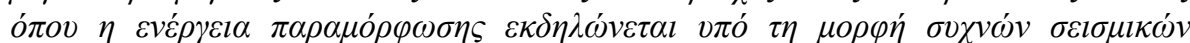

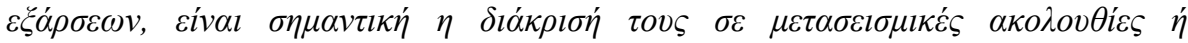

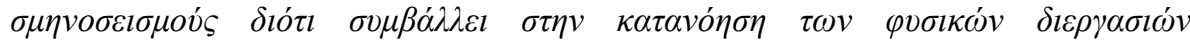

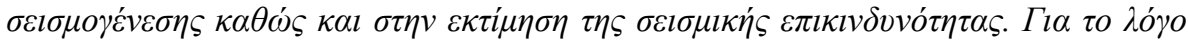

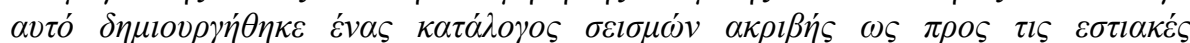

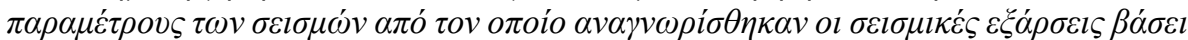

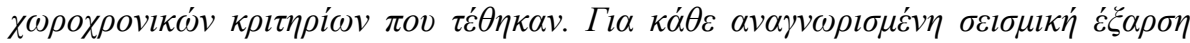

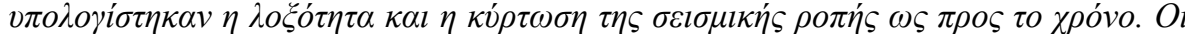

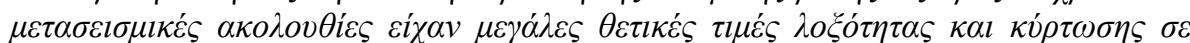

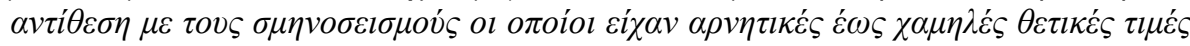




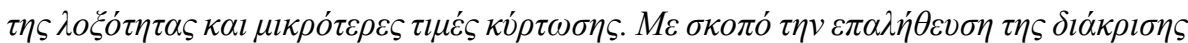

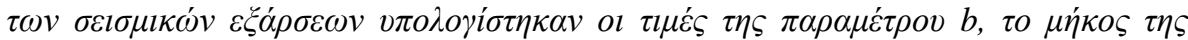

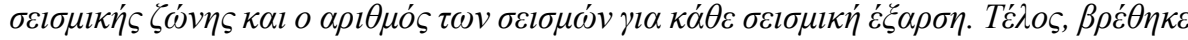

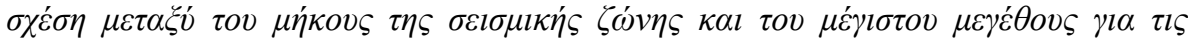

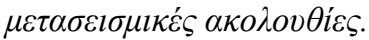

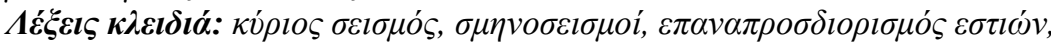

$\lambda o \xi o ́ \tau \eta \tau \alpha, b$-value, $\sigma \tau \alpha \tau \imath \sigma \tau \imath \kappa \eta ́ ~ \sigma \varepsilon \imath \sigma \mu о \lambda o \gamma i \alpha$.

\section{Introduction}

Corinth Gulf (Fig.1) is one of the most seismically active regions in Greece, with several destructive earthquakes both in historical and instrumental eras, and seismicity manifestation with the occurrence of numerous small earthquakes forming sequences of Mainshock - Aftershock (MS-AS) type or earthquake swarms (ES). Spatial and temporal discrimination of these sequences and study of their properties could contribute to understanding of the seismogenesis in the area.

Previous research in the area was conducted by Mesimeri et al. (2015) aiming to classify earthquake clusters to MS - AS and ES for the west part of Corinth Gulf (subregion A on the present study, Fig. 1) and for the period 2011-2014. In this study the seismicity clusters were identified for the entire Corinth Gulf and their classification as MS-AS and ES was attempted. For that purpose statistical parameters as skewness and kurtosis of moment release history were calculated (Mesimeri et al. $2013 ; 2014 ; 2015)$ The difference in magnitude $(\Delta \mathrm{M})$ of the two largest events in each cluster was taken into account as an additional criterion along with the values of skewness and kurtosis. In order to verify the classification of each cluster, other parameters such as b-value, spatial size and the number of events in each cluster were identified.

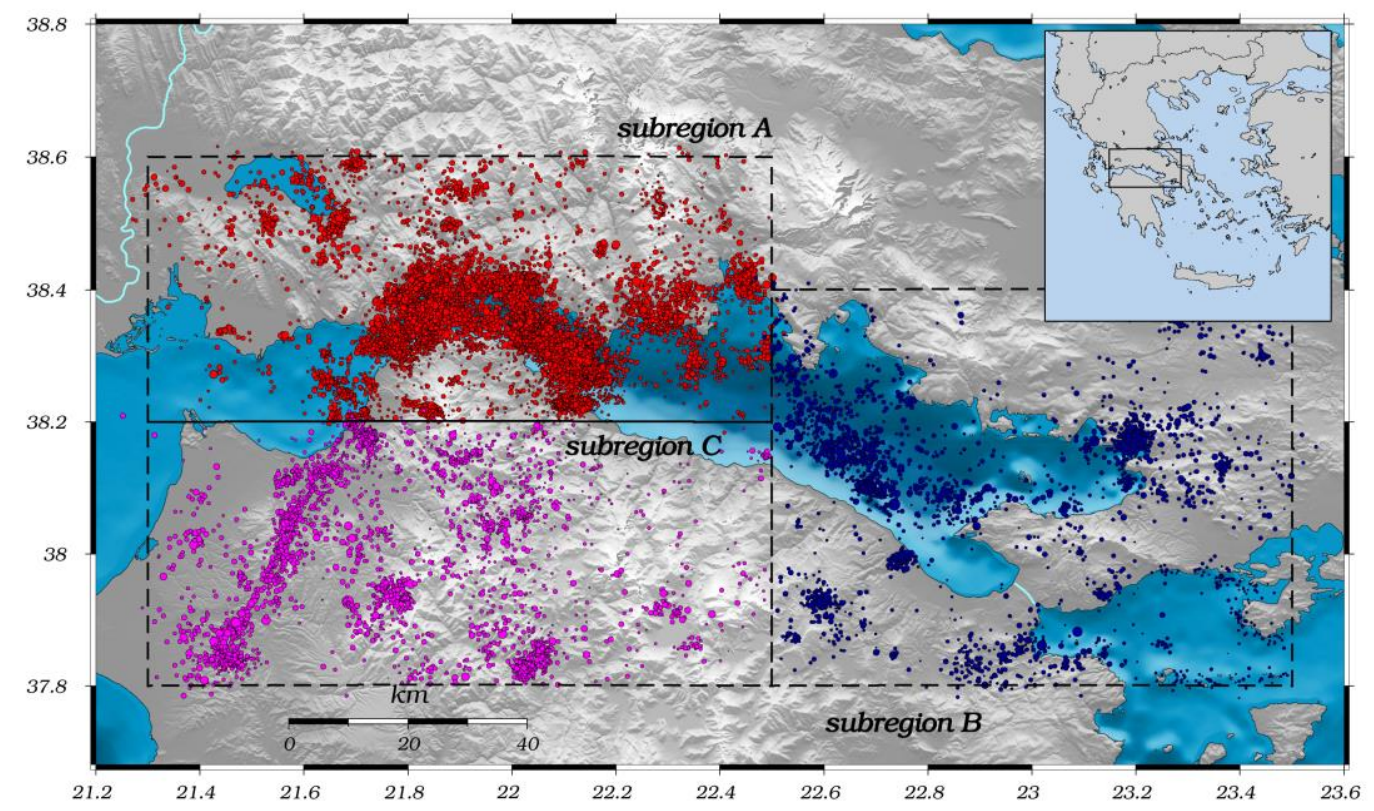

Figure 1 - Seismicity map of Corinth Gulf. 


\section{Data and Methods}

\subsection{Relocation}

In order to investigate spatio-temporal characteristics of the study area it is necessary to compile an earthquake catalogue with as much as possible accurate locations. For that purpose, the recordings of approximately 50 stations of the Hellenic Unified Seismological Network (HUSN) operating during 2011-2014 and located in epicentral distances less than $160 \mathrm{~km}$ from the study area were used. $\mathrm{P}$ and $\mathrm{S}$ phases were mainly gathered from the monthly bulletins of the Geophysics Department of Aristotle University of Thessaloniki (http://geophysics.geo.auth.gr/ss) and the National Observatory of Athens (http://bbnet.gein.noa.gr/HL/) for approximately 24,000 events. Earthquake location was performed after dividing the region into 3 sub-regions, as shown in Figure 1, in order to calculate station delays for smaller areas, a procedure that improves location accuracy. The regional crustal model proposed by Rigo et al. (1996) was used and a new velocity ratio was estimated for each sub-region using the Wadati method. For further improving location accuracy, time corrections for each station were calculated and taken into account in the location procedure. Then, for each sub-region the focal coordinates were re-estimated using the double difference technique (Waldhauser, 2001).

\subsection{Declustering}

Initially for each sub-region the magnitude of completeness $\left(\mathrm{M}_{\mathrm{c}}\right)$ was sought using the maximum curvature method (Wiemer and Wyss, 2000). For each of the sub-regions A, B, C the threshold magnitude was found to be equal to $\mathrm{M}_{\mathrm{c}}=1.1, \mathrm{M}_{\mathrm{c}}=1.5$ and $\mathrm{M}_{\mathrm{c}}=1.4$ respectively. Earthquake clusters were identified after declustering the complete catalogues applying Reasenberg's algorithm (1985) as it has been written in Zmap software (Wiemer, 2001), for MATLAB platform.

The algorithm requires as input the minimum $\left(\mathrm{T}_{\min }\right)$ and maximum $\left(\mathrm{T}_{\max }\right)$ duration of the earthquake sequence in days, the interaction zone in $\mathrm{km}\left(\mathrm{R}_{\text {fact }}\right)$, the probability of an earthquake $\left(\mathrm{P}_{1}\right)$ being part of a seismic excitation and the magnitude of completeness. Different sets of parameters were examined concerning the interaction zone and the duration. For the interaction zone a value of $1 \mathrm{~km}$ was chosen after the examination of values between 1 and $5 \mathrm{~km}$, and for the duration one day. Clusters with more than 10 events were kept according to the criterion of Mogi (1963). For the sake of comparison the CURATE (Cumulative RATE) method (Jacobs et al., 2013), which uses seismicity rate as the main link between earthquakes, was applied. The obtained results by both the algorithms were quite similar and for the purposes of the current study Reasenberg's algorithm was used.

\subsection{Skewness - kurtosis}

One simple way to quantitatively identify earthquake clusters with swarm-like properties is through characterizing the timing of the largest event relative to the rest of the seismicity (Roland and McGuire, 2009; Chen and Shearer, 2011). To accomplish this task, the skewness (S) of moment release history and the kurtosis $(\mathrm{K})$ for each cluster were calculated. Initially for each cluster we normalize the time for each event since the beginning of the sequence

\section{Equation 1- Mean time delay}

$t_{i}=\frac{\left(T_{i}-T_{o}\right)}{\operatorname{mean}\left(T_{i}-T_{o}\right)}, i=1, N . \mathrm{t}_{\mathrm{i}}=\frac{\left(\mathrm{T}_{\mathrm{i}}-\mathrm{T}_{\mathrm{o}}\right)}{\operatorname{mean}\left(\mathrm{T}_{\mathrm{i}}-\mathrm{T}_{\mathrm{o}}\right)} \mathrm{i}=1, \mathrm{~N}$

Then, for each event in a cluster, the moment is estimated from the catalogue magnitude (Hanks and Kanamori, 1979)

\section{Equation 2}

$$
M_{o}(i)=10^{1.5 M_{w}(i)+16.1}
$$


where $\mathrm{M}_{\mathrm{w}}$ is the moment magnitude for each earthquake. The centroid time of moment release is obtained from the weighted mean time

\section{Equation 3 - Centroid time}

$\bar{t}=\frac{\sum_{1}^{N} t_{i} \cdot M_{o}(i)}{\sum_{1}^{N} M_{o}(i)}$.

Individual moments $\left(\mathrm{M}_{\mathrm{o}}\right)$ are normalized by

\section{Equation 4}

$m_{o}(i)=\frac{M_{o}(i)}{\sum_{1}^{N} M_{o}(i)}$.

The third $\left(\mu_{3}\right)$ and the fourth $\left(\mu_{4}\right)$ central moment of this sequence are given by

\section{Equation 5 - Third central moment}

$\boldsymbol{\mu}_{3}=\sum_{1}^{\mathrm{N}}(\mathrm{ti}-\overline{\mathrm{t}})^{3} \mathrm{~m}_{\mathrm{o}}(\mathrm{i}) \sum_{1}^{N}\left(t_{i}-\bar{t}\right)^{3} m_{o}(i), \quad \quad \boldsymbol{\mu}_{4}=\sum_{1}^{\mathrm{N}}(\mathrm{ti}-\overline{\mathrm{t}})^{4} \mathrm{~m}_{\mathrm{o}}(\mathrm{i})$

Equation 6 - Fourth central moment

$$
\sum_{1}^{N}\left(t_{i}-\bar{t}\right)^{4} m_{o}(i)
$$

and the standard deviation:

\section{Equation 7 - Standard deviation}

$\sigma=\sqrt{\sum_{1}^{N}\left(t_{i}-\bar{t}\right)^{2} m_{o}(i)} \cdot \sqrt{\sum_{1}^{\mathrm{N}}(\mathrm{ti}-\overline{\mathrm{t}})^{2} \mathrm{~m}_{\mathrm{o}}(\mathrm{i})}$

The skewness and the kurtosis of moment release of each sequence are

\section{Equation 8 - Skewness}

skewness $=\mu_{3} / \sigma^{3}$,

\section{Equation 9 - Kurtosis}

kurtosis $=\mu_{4} / \sigma^{4}$.

As described by Roland and McGuire (2009) a larger positive value of skewness is expected for MS-AS sequences (approximately 30) and negative or low positive values for ES (between -2 to 2). Chen and Shearer (2011) classified clusters with $\mathrm{t}_{\max } \leq 0.4$ as early $\mathrm{M}_{\max }$ (more similar to MS-AS) and clusters with $t_{\max } \geq 0.4$ as late $M_{\max }$ (more swarm like), where $t_{\max }$ is the normalized timing of the largest event in the cluster. In addition to these criteria, values of kurtosis of the seismic moment release history were calculated for each cluster, where larger and lower values of kurtosis characterize the MS-AS and swarm-like sequences (Mesimeri et al., 2013), respectively. Finally, the parabolic relationship between these parameters was tested.

\section{4. b-value}

The slope of the magnitude frequency distribution (b-value) describes the relative distribution of small and large earthquakes (Gutenberg and Richter, 1944; Ishimoto and Iida, 1939). Its value spans 
from 0.5 to 2.5 and depends on material heterogeneity, fluid intrusion and applied stress (e.g. Scholz, 1968). For the estimation of b-value we used the maximum likelihood method was used (Aki, 1965):

\section{Equation 10- b value calculation}

$b=\frac{1}{\bar{M}-M_{\min }} \log e$

where $\bar{M}$ is the mean and $\mathrm{M}_{\min }$ the minimum magnitude of the given sample. The uncertainty in the estimation of $b$-value is calculated using equation 11 :

\section{Equation 11 - error of $b$ value calculation}

$S=\frac{b}{\sqrt{N}}$

where $\mathrm{N}$ is the number of events in each cluster.

\subsection{Spatial size of earthquake clusters}

The spatial extent of each earthquake cluster was estimated by calculating the radius of gyration. This approach was proposed by Potanina et al. (2011) according to equation 12:

Equation 12 - Radius of gyration

$$
R_{g}=\sqrt{\frac{1}{N} \sum_{i=1}^{N}\left[\left(x_{i}-X_{o}\right)^{2}+\left(y_{i}-Y_{o}\right)^{2}+\left(z_{i}-Z_{o}\right)^{2}\right]}
$$

where $X_{0}, Y_{o}$ and $Z_{o}$ are the average coordinates of the events in each cluster that determine the coordinates of barycenter.

\subsection{Classification of earthquake clusters}

Classification of earthquake clusters as MS-AS and ES was based on several criteria. Firstly the difference in magnitude of the two largest shocks in the sequence $(\Delta \mathrm{M})$ was taken into consideration. According to Båth (1965) the difference in magnitude of the two largest events for a MS-AS sequence is approximately 1.2. Hence, we seek for low values for ES and larger for MS-AS sequences. The obtained values were compared to skewness and kurtosis for each cluster and then the clusters are characterized as MS-AS and ES. Finally, the value of $t_{\max }$ is examined as an applicability criterion for the discrimination of clusters.

\section{Results}

Calculations were conducted for each sub-region separately due to their differences in $\mathbf{M}_{\mathrm{c}}$. In particular, for sub-region A, 83 clusters were identified with $\mathrm{N} \geq 10$ out of a complete data set containing 10,859 events. Regarding their classification, 31 clusters were characterized as MS-AS and 52 as ES. This classification was based on the difference of the two largest earthquakes in each cluster and the values of skewness and kurtosis. A mean value of $\Delta \mathrm{M}=0.3$ was found for $\mathrm{ES}$ and 0.8 for MS-AS. ES present low values of skewness $(S<2)$ and kurtosis $(K<10)$ contrary to MS-AS which present higher values $(S>25$ and $K>700$ ). However, there are clusters with $2<S<25$ and $10<K<700$ that could not be categorized clearly. Some of these are characterized as MS-AS but there are also others with very low $\Delta \mathrm{M}$ (eg. 0.1 ). In order to properly characterize these clusters a more detailed study is necessary concerning their duration. Finally, $79 \%$ of ES have $t_{\max } \geq 0.4$ with a total mean value of 0.83 and $65 \%$ of the MS-AS have $t_{\max }<0.4$ with a total mean value of 0.28 .

For sub-region $\mathrm{B}$, seven clusters were identified with $\mathrm{N} \geq 10$ out of a complete catalog containing 1,574 events. Six of the clusters are characterized as ES with $\mathrm{S}<2, \mathrm{~K}<10$ and a mean $\Delta \mathrm{M}=0.2$. 
Furthermore, Five of the ES have $t_{\max } \geq 0.4$ and the MS-AS have $t_{\max }<0.40$. For sub-region C, 8 clusters were identified with $\mathrm{N} \geq 10$ out of a complete catalog containing 1,987 events. Five of the clusters are characterized as ES and three as MS-AS. ES have values of $\mathrm{S}<2, \mathrm{~K}<10$, a mean $\Delta \mathrm{M}=0.4$ with three of them having $t_{\max } \geq 0.4$. The MS-AS sets have $S>2, K>10$, a mean $\Delta M=1.3$ and all of them have $t_{\max }<0.40$.

Combining all the calculated values of skewness and kurtosis a parabolic relation (Eq. 4, Fig. 2) was derived:

\section{Equation 13 - Parabolic relation between skewness (S) and kurtosis (K)}

$K=0.96 S^{2}+7.13 S-0.42$.

ES have low values of skewness and kurtosis and are placed on the low left part of the parabola whereas the MS-AS type sequences are on the right part.

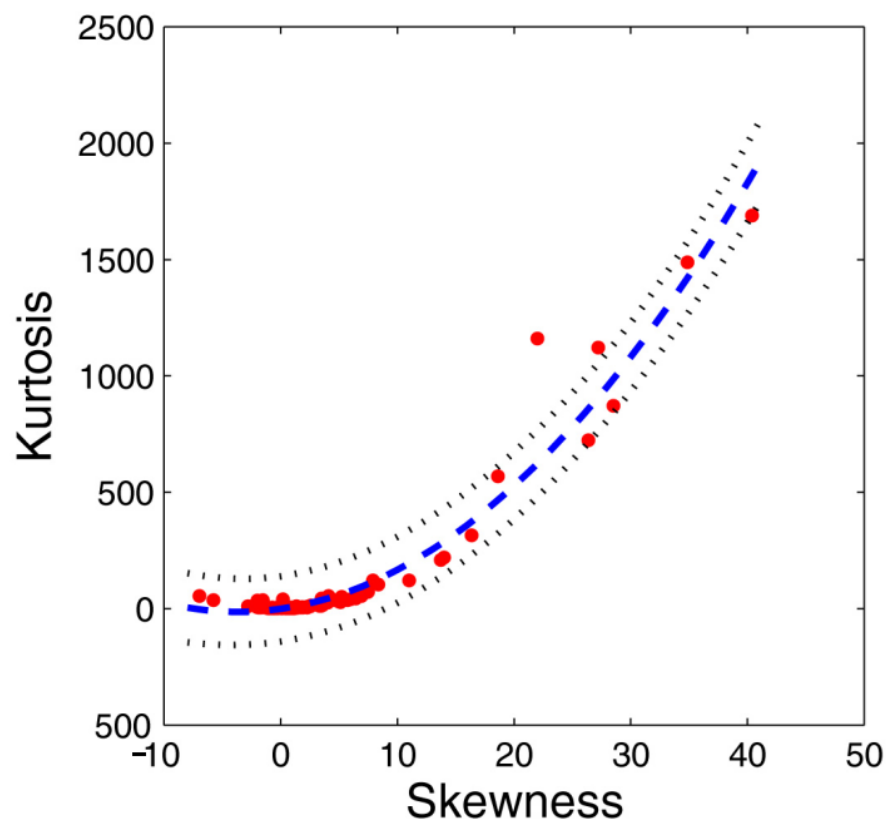

Figure 2 - Parabolic relationship between skewness and kurtosis for the identified clusters.

The b-value for each cluster was calculated along with its uncertainty. The clusters classified as ES have higher b values in comparison to MS-AS clusters (Fig. 3). MS-AS have a mean b value equal to 0.72 whereas the mean value of $b$ for ES equal to 0.93 . The results of b-values are in good agreement with the earlier discrimination of earthquake cluster. There are few cases that exhibit large errors in both ES and MS-AS sequences or the b value is extremely high or low. Large dispersion of the data is most probably due to the small number of events in each cluster, which increases the uncertainty in the estimation as well as the small magnitude range in each cluster.

Scaling relations between geometrical properties of the causative fault and magnitude for a typical MS-AS sequence are well known in literature (e.g. Wells and Coppersmith, 1994; Papazachos et al., 2004). Similar relations are not valid for ES as their spatial size is not depending on the maximum magnitude in the sequence. In Figure 4 the length of each cluster $\left(R_{g}\right)$ against the maximum magnitude in it $\left(\mathrm{M}_{\max }\right)$ was plotted keeping the previous classification. Apparently ES form a cloud and a linear regression is not applicable to the data. The values of the spatial size are between 2 and $8.6 \mathrm{~km}$ with magnitudes from 1.7 to 4.3 with most of the swarms having $\mathrm{M}_{\max }<3.2$. On the other 
hand, MS-AS sequences could be well described by a linear relationship (Eq.14) for magnitudes spanning from 3.1 to 4.8 .
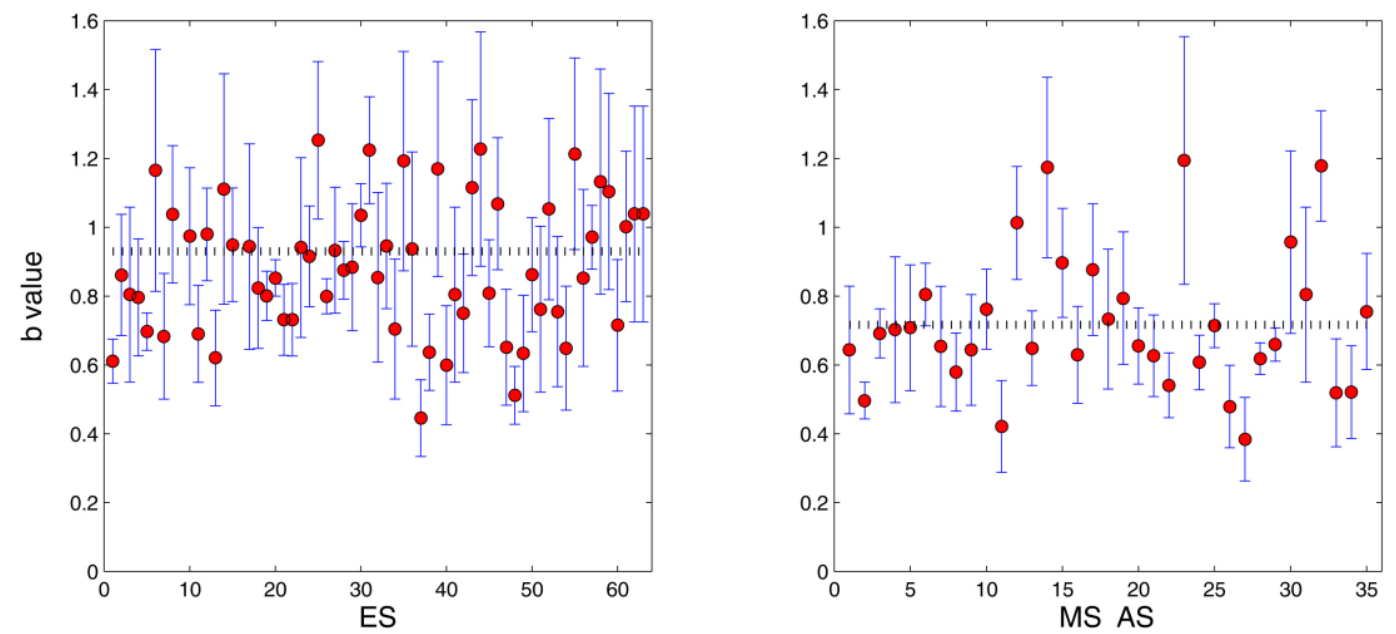

Figure 3 - b-values along with their errors for the ES (left) and MS-AS (right). The mean value of $b$ in each dataset is shown with dashed line.

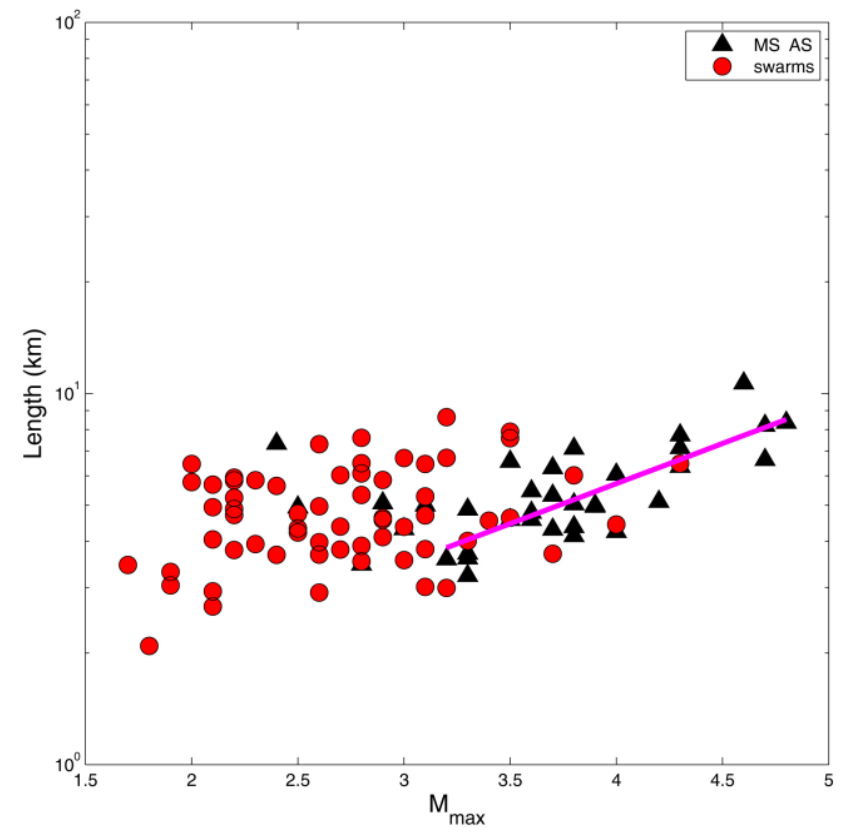

Figure 4 - Length of the activated area against maximum magnitude in each cluster. With circles and triangles are shown the clusters classified as ES and MS-AS, respectively.

Equation 14 - Scaling relation Magnitude Length

$\log L=0.21 M-0.10 \quad 3.1<\mathrm{M} \leq 4.8$

Figure 5 shows that for $\mathrm{M}_{\max } \leq 2.6$ the number of events occurring in an ES is not depending on the largest event in the swarm. For $\mathrm{M}_{\max }>2.6$ the number of events is increasing considerably, showing 
a dependence on the $\mathrm{M}_{\max }$, although there is a big scattering of the data. For equal $\mathrm{M}_{\max }$, the number of events in the MS-AS clusters is less than the number of events in ES with the same $\mathrm{M}_{\max }$.

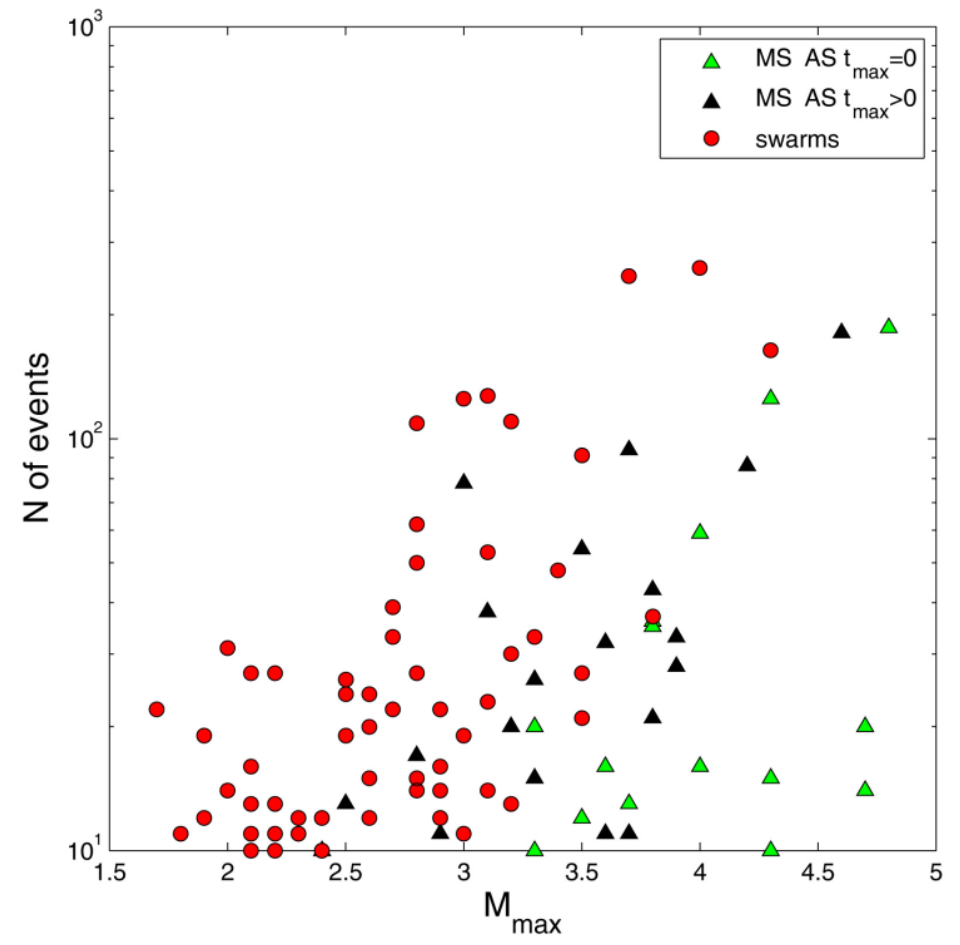

Figure 5 - Number of events in each cluster against maximum magnitude in the cluster. With circles are shown the clusters classified as ES, green triangles represent MS-AS with the mainshock to be the first in the sequence $\left(t_{\max }=0\right)$ and black triangles represent MS-AS with the mainshock occurred later in the sequence $\left(t_{\max }>0\right)$.

\section{Discussion - Conclusions}

The west part of Corinth Gulf (sub-region A) is complex, with highly clustered seismicity in space and time. Distinction of earthquake clusters into MS-AS and ES was attempted. Generally, ES are presenting low values of skewness and kurtosis contrary to MS-AS which exhibit higher values. For sub-regions B and C fewer clusters were identified and their classification into MS-AS and ES is clear. ES in these sub-regions show low values of skewness and kurtosis, and MS-AS have higher ones. In addition, $\mathrm{t}_{\max }$ tends to be a valuable parameter which could be used carefully for the classification of earthquake clusters. The parabolic relationship between skewness and kurtosis along with their values could be applied as a criterion for distinguishing MS-AS sequences from ES. This procedure could be used as a preliminary estimation when a seismic excitation is in progress, investigating its evolution in time by re-evaluating the values as a function of time.

The above results were also verified with the values of $b$ and the spatial size of each cluster. The spatial size of ES seems to be magnitude independent with high b-values to be estimated. A scaling relation between magnitude and length of the rupture area was found for MS-AS sequences, where the $\mathrm{b}$ values were lower or equal to 1 , as expected from already known published work.

The combined results for all sub-regions show that the classification of earthquake clusters is possible by applying the same criteria in the entire region of Corinth Gulf. Characteristics of ES and MS-AS are the same for all sub-regions even though the clusters in sub-regions B and C are fewer. The highly clustered seismicity in sub-region A is probably due to tectonic properties of the area. 
Few cases which cannot be categorized into a certain type of sequence may be the consequences of wrong discrimination of clusters. Future work will use more precise locations after the application of relocation with waveform cross correlation data for better spatial distribution of earthquake clusters. In addition more effort is needed to define accurately the beginning and the end of seismic excitations with more strict temporal criteria. All of these will strengthen our findings and the two types of seismic excitations will be related to tectonic features of the area.

\section{Acknowledgments}

The constructive comments of two anonymous reviewers are greatly appreciated. The map was plotted using Generic Mapping Tools software (Wessel and Smith, 1998). Geophysics Department Contribution 852 .

\section{References}

Aki, K., 1965. Maximum Likelihood Estimate of b in the Formula $\log \mathrm{N}=\mathrm{a}-\mathrm{bM}$ and its Confidence Limits, Bull. Earthq. Res. Inst. Univ. Tokyo, 43(7), 237-239.

Båth, M., 1965. Lateral inhomogeneities of the upper mantle, Tectonophysics, 2(6), 483-514, doi: 10.1016/0040-1951(65)90003-X.

Chen, X. and Shearer, P. M., 2011. Comprehensive analysis of earthquake source spectra and swarms in the Salton Trough, California, J. Geophys. Res., 116(B09), doi: 10.1029/2011JB008263.

Gutenberg, B. and Richter, C.F., 1944. Frequency of earthquakes in California, Bull. Seismol. Soc. Am., 34(5), 184-188.

Hanks, T.C. and Kanamori, H., 1979. A moment magnitude scale, J. Geophys. Res., 84, 2348-2350.

Ishimoto, M. and Iida, K., 1939. Observations of earthquakes registerd with the microseismograph constructed recently, Bull. earthq. Res. Inst., 17(5), 443-478.

Jacobs, K.M., Smith, E.G.C., Savage, M.K. and Zhuang, J., 2013. Cumulative rate analysis (CURATE): A clustering algorithm for swarm dominated catalogs, J. of Geophys. Res., 118(2), 553-569, doi: 10.1029/2012JB009222.

Mesimeri, M., Papadimitriou, E., Karakostas, V. and Tsaklidis, G., 2013. Earthquake clusters in NW Peloponnese, Bull Geol. Soc. Greece,. XLVII/3, 1167-1176.

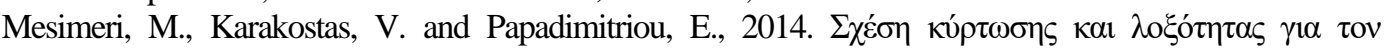

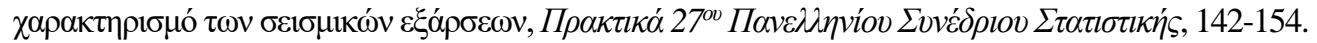

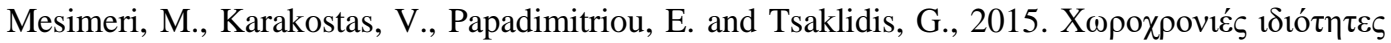

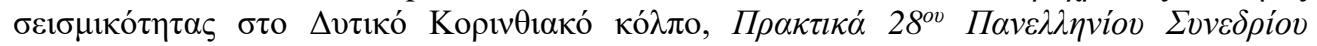
$\sum \tau \alpha \tau \iota \sigma \tau \iota \kappa \dot{s}$.

Mogi, K., 1963. Some discussions on aftershocks, foreshocks and earthquake swarms - the fracture of a semi-infinite body caused by an inner stress origin and its relation to the earthquake phenomena., Bull. Earthq. Res. Inst. Univ. Tokyo, 40, 831-853.

Papazachos, B., Scordilis, E., Panagiotopoulos, D., Papazachos, C. and Karakaisis, G., 2004. Global relations between seismic fault parameters and moment magnitude of earthquakes, Bull Geol. Soc. Greece, XXXVI/3, 1482-1489.

Potanina, M.G., Smirnov, V.B. and Bernard, P., 2011. Patterns of seismic swarm activity in the Corinth Rift in 2000-2005, Izvestiya Phys. Solid Earth, 47(7), 610-622.

Reasenberg, P., 1985. Second-order moment of central California seismicity, 1969-1982, J. of Geophys. Res., 90(B7), 5479, doi: 10.1029/JB090iB07p05479.

Rigo, A., Lyon-Caen, H., Armijo, R., Deschamps, A., Hatzfeld, D., Makropoulos, K., Papadimitriou, P. and Kassaras, I., 1996. A micro-seismicity study in the western part of the Gulf of Corinth (Greece): implications for large-scale normal faulting mechanisms, Geophys. J. Int., 126, 663-688.

Roland, E. and McGuire, J.J., 2009. Earthquake swarms on transform faults, Geophys. J. Int., 178(3), 1677-1690.

Scholz, C.H., 1968. The frequency - magnitude relation of microfracturing in rock and its relation 
to earthquakes, Bull. Seismol. Soc. Am, 58(1), 399-415.

Waldhauser, F., 2001. HypoDD-a program to compute double-difference hypocenter locations, US Geological Survey Open File Report.

Wells, D.L. and Coppersmith, K.J., 1994. New empirical relationships among magnitude, rupture length, rupture width, rupture area, and surface displacement, Bull. Seismol. Soc. Am., 84(4), 974-1002.

Wessel, P. and Smith, W.H.F., 1998. New,improved version of the generic mapping tools released', EOS Trans. Am. Geophys. Union, 79(47), 579.

Wiemer, S., 2001. A Software Package to Analyze Seismicity: ZMAP, Seismol. Res. Lett., 72(3), 373-382, doi: 10.1785/gssrl.72.3.373.

Wiemer, S. and Wyss, M., 2000. Minimum magnitude of completeness in earthquake catalogs: Examples from Alaska, the Western United States, and Japan, Bull. Seismol. Soc. Am., 90(4), 859-869, doi: 10.1785/0119990114. 